\title{
A Review of BIM Capabilities for Quantity Surveying Practice
}

\author{
Noor Akmal Adillah Ismail1,3, a , Robin Drogemuller ${ }^{1}$, Scott Beazley ${ }^{2}$ and Robert Owen ${ }^{1}$ \\ ${ }^{1}$ School of Civil Engineering \& Built Environment, Queensland University of Technology, Brisbane, 4001 QLD, Australia \\ ${ }^{2}$ School of Design, Queensland University of Technology, Brisbane, 4001 QLD, Australia \\ ${ }^{3}$ Faculty of Architecture, Planning \& Surveying, Universiti Teknologi MARA, 40450 Shah Alam, Selangor, Malaysia
}

\begin{abstract}
It has been 20 years since the formation of buildingSMART International (then the International Alliance for Interoperability) and the commencement of the development of the Industry Foundation Classes (IFC). Initial uptake of the Building Information Modelling (BIM) concept and the IFCs was very slow, but it is now moving into the mainstream in developed countries. BIM is not as advanced in some countries such as Malaysia that are moving rapidly towards developed status. This paper will review the use of BIM by Quantity Surveyors in both countries that follow the "English" tradition and those, such as the US, which have developed other approaches. It will examine the capabilities of some of the BIM-based cost estimating software as the basis for understanding the use of BIM by Quantity Surveyors. This will include Quantity Surveyors who are using BIM to provide a traditional estimating service, as well as those firms that are applying the new technology to changing roles in cost estimating and cost planning. This will provide the basis for suggestions as to how Malaysian QS firms can exploit this technology.
\end{abstract}

\section{Introduction}

BIM technology has become increasingly well-known among construction industry players throughout the world. It is acknowledged as having contributed towards the success of projects due to its more efficient and effective working practices. This includes its contribution in the preparation of construction cost estimates, the most valuable quantity surveying practice in determining the project costs. BIM is claimed to offer a significant advantage in improving the estimating practice that is often prone to errors and inaccuracies [1]. BIM technology potentially provides a better quality of data by automation of information documentation [2-7]. More specifically, BIM has much to offer when it comes to improving cost estimating reliability, including early schedule information, quicker predictions of cost impact of design changes, better understanding through improved visualisation, as well as the possibility to access additional information for documentation [8]. 3D as-built models containing rich data are replacing traditional 2D methods; BIM creates information integration with a seamless flow of information from the initial phase to the final stage of the life cycle [9]. Information is integrated by the BIM models' controlling the information in a shared repository to establish consistent, accurate and accessible data [2].

Currently, construction industry practice widely employs BIM [10] and its implementation is increasing from year to year [11, 12]. USA, Finland, Denmark, Norway, Netherlands, UK, Australia, Hong Kong \&
Singapore are among the countries heading towards significant BIM uptake [13]. Malaysia, where the growth of BIM has been driven mainly by the private sector since 2009 [14], has made slow progress in developing BIM systems [13], the level of implementation falling on 0 and 1 of the BIM scale [15], indicating the need for a solution in those issues. Thereby, CIDB, as the professional body that has been given the mandate for managing BIM uptake in Malaysia, has urged BIM implementation amongst the construction players in their practice to produce more effective construction projects $[16,17]$. Despite the efforts to encourage BIM usage amongst managerial and operational teams in the Malaysian Construction Industry, CIDB (2013) has reported that the slow level of transformation towards BIM could be due to the lack of standardised BIM processes and the absence of guidelines for its implementation. Hence, the CIDB has emphasized the BIM guidelines to be provided for the construction industry users for better communication and work collaboration [14]. Apart from the CIDB emphasising the provision of BIM guidelines for the industry users, Quek (2012) has specifically suggested the Royal Institution of Surveyors Malaysia (RISM) especially Quantity Surveying (QS) Division, to initiate appropriate actions in evaluating the influence of BIM.

Therefore, this paper aims to overview the impacts of BIM on the role of the Quantity Surveyors. The research method adopted for this paper is a comprehensive literature review of BIM capabilities pertaining to quantity surveying practice specifically in achieving more

\footnotetext{
${ }^{\mathrm{a}}$ Corresponding author: noorakmaladillahbinti.ismail@hdr.qut.edu.au
} 
reliable cost estimates. The first part discusses general BIM usage by Quantity Surveyors and the second part examines the BIM capabilities especially in the use of software in assisting Quantity Surveyors to achieve more dependable results in their cost estimating practice. From the literature review, the BIM capabilities were synthesised into three broad categories according to their importance in estimating cost, including data visualisation, reliable database and data coordination. The results were then hypothesised to affect the reliability of cost estimates in quantity surveying practice, leading to establishing a reliable framework for this paper. This paper also contributes to a holistic perspective on the effects of improved information resulting from BIM adoption through a better understanding and the generation of more knowledge in the production of more reliable cost estimates. This paper builds a framework which could provide the basis for suggestions as to how Malaysian Quantity Surveyors can effectively exploit BIM technology.

\section{BIM usages by Quantity Surveyors}

BIM usage in the construction industry throughout the world has been reported in international survey series such as SmartMarket Reports, National BIM Surveys (NBS), McGraw Hill and Masterspec. A survey by McGraw Hill Construction in the United Kingdom (UK) in 2010 recorded that the BIM adoption rate amongst the construction professionals was $35 \%$, primarily by the architects (60\%), engineers (39\%) and contractors (23\%) respectively. While a National BIM Survey conducted in New Zealand at the end of 2011, showed 34\% of the respondents were aware and currently using BIM, 12\% of them were neither aware nor using BIM and 54\% were just aware of BIM [19]. Significantly, the same survey conducted the next year reported that the result of respondents being aware and currently using BIM had increased to $57 \%$, also neither aware nor using BIM had reduced to $2 \%[20,21]$.

There are numerous benefits BIM could offer by its implementation in the construction industry. It has been documented in the SmartMarket Report that 9 out of 10 BIM users in South Korea (92\%) obtained advantages through using BIM and by having positive views towards BIM values they believe they achieved more from the continuous usage [22]. An online survey executed by McGraw Hill Construction in 2014 recorded that BIM benefits that have been divided into internal, project and process, and are inclusive of: reduced errors \& omissions, collaboration, enhanced image, reduced rework, reduced cost \& time, better cost control, marketing new business, offering new services, increased profits, maintaining repeat business, reduced cycle time of workflows, faster client approval cycles, improved safety, and faster regulatory approval cycles. A questionnaire survey carried out by Newton \& Chileshe (2012) to 29 construction organisations in Australia identified that the BIM benefits that inspire those organisations the most are: improved constructability, improved visualisation, improved productivity, reduced clashes, improved quality
\& accuracy, improved client satisfaction, increased competitiveness, improved information sharing and enhanced sustainability. Thurairajah \& Goucher (2013) through a questionnaire sent to several companies in the $\mathrm{UK}$, summarised that the BIM drivers are: encompassing cost consultant's attitude, improved project collaboration, easier sharing \& obtaining information, increased cost estimates accuracy, improved reliability in cost estimates, supporting early supply chain involvement, early schedule information, quicker predicted cost impact of design changes, improved visualisation and also clash detection.

Specifically, in 2011, the Royal Institution of Chartered Surveyors (RICS) conducted a survey among its members. The responses received from 156 Quantity Surveyors showed that $10 \%$ of them were regularly using $\mathrm{BIM}$, in which the majority use was in the design and construction phases [25]. They mostly used BIM for construction scheduling, extracting quantities and facilities or asset management. The results also showed that $10 \%$ of the respondents were interested in using BIM by actively evaluating BIM tools for their practice. The barriers that were also highlighted in taking up BIM as their practice were the lack in client demand, training, application interfaces and standards. Whereas, Tse, et.al. (2009) evaluated the BIM usage in materials take-off that is generally done by the Quantity Surveyors, by carrying out a BIM case study of a Hong Kong project. It was observed that BIM-based projects provide the Quantity Surveyors substantial involvement especially in the project design process compared to the traditional 2D practice. Even though BIM can perform automatic and accurate quantity take-off it was proved that the knowledge of Quantity Surveyors is still important particularly in generating bills of quantities from the BIM models. Some building elements may not be modelled; hence cannot be measured automatically. Therefore, checking of model geometry is an essential role of Quantity Surveyors.

In New Zealand, Boon and Prigg (2012) found that BIM was only practiced for larger projects among the construction players, which ranked them on the level 1 or 2 of the BIM maturity scale. The interviewed Quantity Surveyors revealed that they had limited experience of extracting quantities from $3 \mathrm{D}$ models. They preferred to work in traditional 2D format. However, the Quantity Surveyors with BIM experience emphasised the benefits of additional information they could retrieve when deriving quantities, by rotating 3D models, which they could not do with 2D drawings. In Australia, results were received from a BIM adoption survey amongst quantity surveying firms conducted by Aibinu and Venkatesh (2013). From 40 responses obtained, $37 \%$ of the respondents have been using BIM for their projects. Most of them have little experience of using 3D models to extract quantities, in which they only used 3D models for visualisation predominantly at cost planning stage. Usually, for BIM-based projects, they were not issued with 3D BIM developed by designers; rather, they were still using 2D drawings for quantity take-off and cost estimation. The drivers that led the firms to initiate BIM included: ease of use, client requirement, quality 
information in models, case studies, industry-wide use, cost-benefit analysis, integration with current software and also scenario training.

It can be seen that BIM adoption is increasing internationally. Realising the potential benefits offered by BIM implementation, the development of BIM in most countries was complemented with policies, standards, guidelines and other approaches to improve BIM usage among the users and also to increase BIM awareness among non-users. Nevertheless, the BIM benefits sought should be explored comprehensively in exploring effective BIM projects. Theoretically, BIM can improve the reliability of cost estimates through numerous benefits offered by the technology that affect the many factors on which the estimates depend. Quantity Surveyors, as qualified estimators, should take the initiative on these issues. As such, it is crucial to identify BIM capabilities towards quantity surveying practice, before any estimate.

\section{BIM capabilities for quantity surveying practice}

A reliable cost estimate demands accurate building information to minimise estimation errors, especially in the early phase process [29]. As described by Monteiro and Martins (2013), using 2D measurements and 2D designs can lead to errors and omissions throughout the various construction stages, which lead to inaccurate estimation for budgeting. BIM implementation specifically plays a significant role in improving information in the early stages of construction projects. It permits better quality of data production by automation of information extraction. This allows BIM applications to contribute to improving the reliability of cost estimates including early schedule information, quick prediction of cost impact on design changes, better understanding through visualisation, and also access to information for documentation.

BIM tools provide more detailed and accurate cost estimates for construction projects, with the availability of geometric properties for building elements in producing spatial quantities, such as area and volume [30]. A pilot study conducted by Shen and Issa (2010) proved that a significant improvement was achieved through the application of BIM tools to increase the efficiency and accuracy of cost estimates, compared to the traditional estimating method, and this application was sufficient even by using only the function of $3 \mathrm{D}$ visualisation. Additionally, Choi, et al. (2015) outlines specific processes on how BIM is used in quantitytaking-off for schematic estimation in the early design stage, to improve cost estimates reliability. The process steps include verification of the physical quality of elements to increase the accuracy of calculated quantities, as well as the verification of input data for estimation. These processes address the issues of low reliability in cost estimates that are performed manually. The reliability of cost estimates can be improved through the implementation of BIM technology. Improved information, especially through its data visualisation, reliable database and data coordination, as the significant input in estimating construction costs, is among the valuable assets BIM can deliver to potentially improve quantity surveying practice; also, being able to compare models as they developed or changed. Table 1 below tabulates the BIM capabilities towards performing more reliable cost estimates in quantity surveying practice through the three categories of improved information including data visualisation, reliable database and data coordination.

Table 1. Categories of BIM capabilities towards QS practice.

\begin{tabular}{|c|c|}
\hline Categories & BIM capabilities \\
\hline \multirow{5}{*}{ Data visualisation } & - 5D life cycle costing analysis \\
& [32] \\
& - BQ preparation with 3D \\
& views [33] \\
& design planning [34] \\
& - Simulation, cost control, \\
& value engineering, \\
& estimating, tendering [34] \\
& - Drawing interpretation, data \\
& extraction [35] \\
\hline \multirow{5}{*}{ Reliable database } & - IFC view for BQ [36] \\
& - Quantity take-off, cost \\
& estimating [37] \\
& - Estimating, tendering [34] \\
& - Post construction cost \\
& management [34] \\
& - Design changes identification \\
& {$[35]$} \\
\hline \multirow{5}{*}{ Data coordination } & - Virtual models, estimating \\
& [34] \\
& - Communication, access to \\
& information [35] \\
\hline
\end{tabular}

\subsection{Data visualisation}

Concern about effective project management leads not only to an emphasis on supplying adequate and extensive information about the project related, but also on equipping the project with visualisation tools to facilitate information delivery [38]. Dahl, et. al. (2001) refer to visualisation as visual mental images used to allow the generation, interpretation and manipulation of information through spatial representation. While visualisation tasks are divided into three groups, i.e. information retrieval, information analysis and information dissemination, the second part, information analysis, is the most valuable in obtaining insight from data [40]. Compared to understanding textual information, visualisation leads to far more effective analysis. In general, visualisation assists team members to better understand what will be constructed through $3 \mathrm{D}$ model views [41] in which the visualisation models not only represent building detailed properties, but also simulate their interaction and movement [42]. Digital models, which can be used for simulation and 
visualisation at any stage [43], enable constructionsequence visualisation [44] and allow the construction team to better understand what they intend to build [45].

Furneaux and Kivvits (2008) claim the visualisation process demonstrating project stages from the beginning to the end of construction projects especially help nontechnical people to understand and identify issues. The respondents to the Rajendran, et. al. (2014) study agreed that the 2D drawings in traditional methods could not demonstrate clear visualisation, and this has led to numerous design problems in the construction industry. However, BIM improves this by providing clear buildingvisualisation settings for a better understanding of a building design. With rich 3D design-visualisation content in BIM modelling and analysis to help the team understand better [47], BIM is superior to 2D drafting as it allows the team to view a building and its contents from all angles, and at the same time to detect and amend any related issues at earlier stages so as to reduce costly changes [48]. Additionally, Leicht and Messner (1997) differentiate between BIM and traditional methods by describing multiple, dynamic and better $3 \mathrm{D}$ views of a building offered in BIM models, compared to only predefined $2 \mathrm{D}$ views in traditional documents.

\subsection{Reliable database}

A BIM model is created from a database that includes information such as manufacturing data, pricing, physical data (weight, size and material finish) and also data for many other elements incorporated in the building process [48]. Rather than producing a series of separated drawings, digital databases provide an archive of all physical and functional characteristics of output, in which all related information is formed into intelligent objects. BIM projects then adapt these intelligent objects to automatically symbolise the project elements in any plan, elevation, section or detail that can be adjusted parametrically as the design changes [50]. Giving more than ordinary drawings could offer, BIM merges building design, construction and maintenance properties in one beneficial model as a data repository that can be shared by all team members. Therefore, it furnishes the project with more efficient and accurate information as compared to traditional 2D CAD drawings [48]. Being databasedriven, BIM software is a powerful tool that integrates engineering and architectural design elements [51]. Not only does it act as an intelligent model represented by digital objects, but objects can also be counted and sequenced in order to identify relationships. This process then establishes a greater understanding of these relationships, and possibly identifies relevant pre-existing information behind the objects, which is not available in textual information. Architectural elements used in the BIM model are stored in libraries where the complete building model and all of its representations are incorporated in a single BIM database. Consequently, any changes made to the BIM model will influence all related drawings generated from the database. Thus, it enables users to not only generate but also automatically update project documents, with all building information data attached to the building elements [41, 44].

Nagalingam et al. (2013) point out that BIM technology can assist quantity surveyors with their practice through information about the whole building represented in BIM, along with the complete related design documents, which have been stored in an integrated database. This integrated environment allows all parametric information to be interconnected, thereby acknowledging any changes affecting the assembly and construction processes. This makes available exact quantities and specific materials in an electronic format, for design documents for the quantity surveyors to produce their taking-offs and cost estimates. A robust database is established through the parametric elements in which the information gathered from the database raises efficiency standards, hence enhancing communication between the design and construction teams [48]. Furthermore, the BIM database is based on its proprietary classification system and can be compatible with the Industry Foundation Classes (IFC) format [30]. The IFC format, which captures both the geometry and properties of intelligent building objects associated with its relationships within BIM models, allows for information-sharing across a team [48]. The IFC file in which data is arranged based on its classes and properties supports data exchange among BIM application platforms such as Autodesk Revit in exporting and importing the required construction information data files [52].

\subsection{Data coordination}

Boshoff (2014) defines BIM as the generation of coordinated $3 \mathrm{D}$ models that integrate the representation of 3D objects through synchronised 2D drawings. In comparison with the paper-based drawings that are difficult to integrate and coordinate, BIM models have become a solution to this problem, in their ability to effectively communicate vital information between the people in the construction field [50]. This is done by the user developing 3D components in the software and combining them in a single model which shows multiple views of the building model. Where multiple views are possible, this allows any notification throughout the reflected views if any changes are made to the model. Additionally, the information about plans, sections and elevations that has been developed from the same data has been coordinated, and this improves the coordination of information exchange [53], hence translating into better coordination among the design, engineering and construction disciplines [54]. This coordinated information delivery further improves the coordination of construction documentation, consequently reducing errors and reworks [49-54].

All combined models of a project design and construction that have been developed using BIM are located in the BIM database. These models can be viewed simultaneously in order to spot any clashes between architectural, structural, mechanical, electrical and plumbing systems [50]. The systems can be coordinated where all equipment, fixtures, pipes, ducts, conduits, 
structural members and other building components are analysed with "clash detection" tools to check any conflicts before the installation of the system [61]. This would undoubtedly benefit designers and other team members in monitoring which area each is developing to ensure that they have sufficient information, as well as diminishing unwanted conflicts and rework [49]. The BIM model has details on each building component which can be retrieved from its modelled elements, thereby allowing the team members to quickly access the information. With all information being made available for everyone in the team, those responsible are alerted to any design changes and their consequences, which then improves coordination among their team members [48].

\section{Basis for framework}

BIM offers numerous potential benefits including improved information received to be manipulated for design and construction utilisation throughout the project stages. It has been discussed above how data visualisation, reliable database and data coordination, as essential features of BIM technology, could improve information and hence improve the reliability of cost estimates. According to Leicht \& Messner (1997), the components that distinguish BIM and traditional documentation are a visualisation of spatial information, data availability for further analysis, and the existence of information. BIM applications are capable to automatically generate visual information such as floor plans, elevations, 2D and 3D sections, detailed sections, text-based information, model analysis and simulation results. Exchange information is executed via proprietary format within the database without losing data, and the interaction between applications is often ensured through IFC [30]. Its biggest advantage is, more accurate quantities generated from digital model, rapidly and reliably. The IFC that allows information to be shared across the team [48] next permits data coordination within the same shared resources.

This study demonstrates that there are significant relationships between improved information as a benefit to BIM adoption to improve the reliability of cost estimates. The dimensions of improved information being offered by BIM technology are data visualisation, reliable database and data coordination, and these constructs contribute to the reliability of cost estimates required in every construction cost estimating practice. Therefore, a framework as shown in Figure 1 is primarily developed with two primary relationships established. First, the improved information through data visualisation, reliable database and data coordination are achieved by BIM adoption. Secondly, BIM implementation with its benefits of improving project information in a construction project could produce more reliable cost estimates.

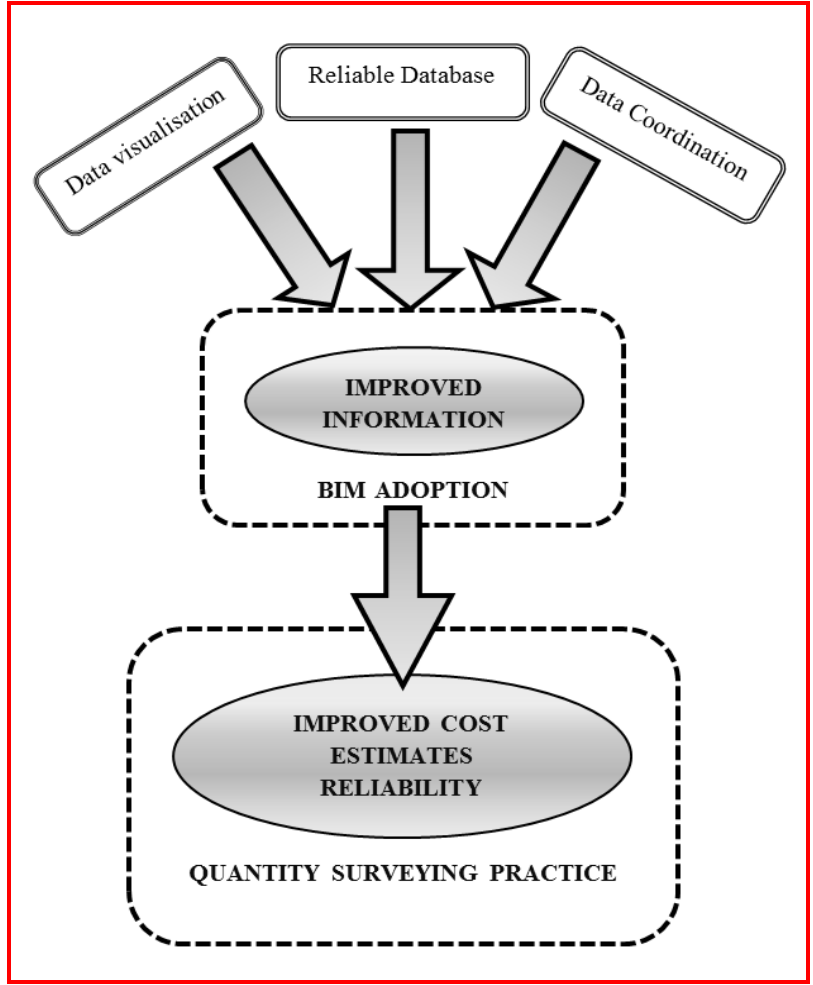

Figure 1. Developed framework

\section{Conclusions}

This study seeks to establish a reliable framework for linking cost estimating practice and BIM implementation. A survey is currently (January 2015) providing evidence which, although incomplete, indicates that that improved information with its dimensions of data visualisation, reliable database and data coordination would potentially be achieved through BIM adoption. By implementing BIM in cost estimation, it would possibly improve input information and enhance estimator's knowledge and understanding which ultimately leading them to produce more reliable cost estimates. This study also contributes in adding collective knowledge in the existing literature regarding BIM implementation and the reliability of cost estimates. It demonstrates the elements of BIM improved information to potentially improve the quantity surveying practice. From a practical perspective, the framework can serve as a guideline to increase the understanding of construction industry stakeholders, especially Quantity Surveyors. It demonstrates how they can implement BIM through its identified benefits by improving quantification data of the project information input they receive for estimating costs. It also guides the Quantity Surveyors as estimators in knowing BIM benefits that can maximise their knowledge and understanding of the project operation and process to assist them in establishing more reliable cost estimates. 


\section{References}

[1] O. A. Olatunji and W. D. Sher, "A Comparative Analysis of 2D Computer-Aided Estimating (CAE) and BIM Estimating Procedures," in Handbook of Research on Building Information Modeling and Construction Informatics: Concepts and Technologies, 2010, pp. 170-189.

[2] CRC Construction Innovation, "Adopting BIM for facilities management: Solutions for managing the Sydney Opera House," 2007.

[3] C. Furneaux and R. Kivvits, "BIM - Implications for Government," 2008.

[4] D. Bryde, M. Broquetas, and J. M. Volm, "The project benefits of Building Information Modelling (BIM)," Int. J. Proj. Manag., vol. 31, pp. 971-980, 2013.

[5] S. Kalinichuk and A. Tomek, "Construction Industry Products Diversification by Implementation of BIM," Int. J. Eng. Technol. Innov., vol. 3, no. 4, pp. 251-258, 2013.

[6] B. Abbasnejad and H. I. Moud, "BIM and Basic Challenges Associated with its Definitions, Interpretations and Expectations," Int. J. Eng. Res. Appl., vol. 3, no. 2, pp. 287-294, 2013.

[7] G. Nagalingam, H. S. Jayasena, and K. A. T. O. Ranadewa, "Building Information Modelling and Future Quantity Surveyor's Practice in Sri Lankan Construction Industry," in The Second World Construction Symposium 2013: SocioEconomic Sustainability in Construction, 2013, pp. 81-92.

[8] N. Thurairajah and D. Goucher, "Advantages and Challenges of Using BIM : a Cost Consultant's Perspective," in 49th ASC Annual International Conference Proceedings, 2013.

[9] J. D. Goedert and P. Meadati, "Integrating Construction Process Documentation into Building Information Modeling," J. Constr. Eng. Manag., vol. 134, pp. 509-516, 2008.

[10] G. Kim, H. Park, and J. Shin, "An Assessment of the Accuracy of Cost Estimation Using Building Information Modeling in Design Process," Appl. Mech. Mater., vol. 291-294, pp. 2822-2825, 2013.

[11] RICS, "International BIM implementation guide," 2014.

[12] McGraw Hill Construction, "SmartMarket Report: The Business Value of BIM for Construction in Major Global Markets," 2014.

[13] J. K. Quek, "Strategies and Frameworks for Adopting Building Information Modelling (BIM) for Quantity Surveyors," Appl. Mech. Mater., vol. 174-177, pp. 3404-3419, 2012.

[14] CIDB, "Issues and challenges in implementating BIM for SME's in the construction industry," 2013.

[15] Z. Zahrizan, N. M. Ali, A. T. Haron, A. Marshallponting, and Z. Abd, "Exploring the Adoption of Building Information Modelling (BIM) in the Malaysian Construction Industry: A Qualitative Approach," IJRET Int. J. Res. Eng. Technol., vol.
2, no. 8, pp. 384-395, 2013.

[16] CIDB, "BIM in Malaysia," 2013. [Online]. Available: www.bimcenter.com.my.

[17] Bernama, "Adopt BIM technology, CIDB urges industry players," Daily Express, 23-Sep-2014.

[18] McGraw Hill Construction, "SmartMarket Report: The Business Value of BIM in Europe," 2010.

[19] Masterspec, "New Zealand National BIM Survey 2012," 2012.

[20] Masterspec, "New Zealand National BIM Survey 2013," 2013.

[21] NBS, "NBS International BIM Report 2013," 2013.

[22] McGraw Hill Construction, "SmartMarket Report: The Business Value of BIM in South Korea," 2012.

[23] McGraw Hill Construction, "SmartMarket Report: The Business Value of BIM for Owners," 2014.

[24] K. Newton and N. Chileshe, "Awareness, Usage and Benefits of Building Information Modelling (BIM) Adoption - The Case of The South Australian Construction Organisations," in Procs 28th Annual ARCOM Conference, 2012, pp. 312.

[25] BCIS, "RICS 2011 Building Information Modelling Survey Report," 2011.

[26] K. T. Tse, A. K. Wong, and F. K. Wong, "Building information modelling in material takeoff in a Hong Kong project," in Collaborative Construction Information Management, 1st ed., G. Q. Shen, P. Brandon, and A. N. Baldwin, Eds. New York: Spon Press, 2009, pp. 186-197.

[27] J. Boon and C. Prigg, "Evolution of Quantity Surveying Practice in the Use of BIM - the New Zealand Experience," in Proceedings of the CIB International Conference on Management and Innovation for a Sustainable Built Environment., 2012, pp. 84-98.

[28] A. Aibinu and S. Venkatesh, "Status of BIM Adoption and the BIM Experience of Cost Consultants in Australia," J. Prof. Issues Eng. Educ. Pract., 2013.

[29] J. Choi, H. Kim, and I. Kim, "Open BIM-based quantity take-off system for schematic estimation of building frame in early design stage," $J$. Comput. Des. Eng., vol. 2, no. 1, pp. 16-25, 2015.

[30] A. Monteiro and J. P. Martins, “A survey on modeling guidelines for quantity takeoff-oriented BIM-based design," Autom. Constr., vol. 35, pp. 238-253, 2013.

[31] Z. Shen and R. R. A. Issa, "Quantitative evaluation of the BIM-assisted construction detailed cost estimates," J. Inf. Technol. Constr., vol. 15, pp. 234-257, 2010.

[32] F. P. Lai, D. Halvitigala, J. Boon, and R. Birchmore, "How can BIM Technology assist in optimising the Life Cycle Cost of a Building?," in 16th Pacific Rim Real Estate Society Conference, 2010. 
[33] A. Nadeem, A. K. D. Wong, and F. K. W. Wong, "Bill of Quantities with 3D Views Using Building Information Modeling," Arab. J. Sci. Eng., vol. 40, no. 9, pp. 2465-2477, 2015.

[34] O. A. Olatunji and W. Sher, "Perspectives on Estimating Practices Modelling," Australas. J. Constr. Econ. Build., vol. 14, no. 4, pp. 32-53, 2014.

[35] C. Harrison and D. Thurnell, "BIM Implementation in a New Zealand Consulting Quantity Surveying Practice," Int. J. Constr. Supply Chain Manag., vol. 5, no. 1, pp. 1-15, 2015.

[36] K. U. Gokce and H. U. Gokce, "IFC View for Bill of Quantities for Software Interoperability," in Proceedings of the 30th CIB W78 International Conference, 2013, pp. 827-836.

[37] E. Plebankiewicz, K. Zima, and M. Skibniewski, "Construction cost and time planning using BIMbased applications," in Creative Construction Conference, 2015, pp. 537-545.

[38] T.-H. Chuang, B.-C. Lee, and I.-C. Wu, "Applying Cloud Computing Technology To BIM Visualization and Manipulation," in 28th International Symposium on Automation and Robotics in Construction, 2011, pp. 144-149.

[39] D. W. Dahl, A. Chattopadhyay, and G. J. Gorn, "The importance of visualisation in concept design," Des. Stud., vol. 22, no. 1, pp. 5-26, 2001.

[40] M. Chen and L. Floridi, "An analysis of information visualization," Syntheses, vol. 190, pp. 3421-3438, 2013.

[41] M. Ali, T. Haron, and A. Marshall-ponting, "Exploring the Barriers and Driving Factors in Implementing Building Information Modelling ( BIM ) in the Malaysian Construction Industry : A Preliminary Study," J. Inst. Eng. Malaysia, vol. 75, no. 1, pp. 1-10, 2014.

[42] CRC Construction Innovation, National guidelines for digital modelling. 2009.

[43] A. Z. Sheth and S. M. Malsane, "Building Information Modelling, a Tool for Green Built Environment," in All India Seminar on Innovation in Green Building Technology, Green Build 2014, 2014.

[44] R. Eadie, H. Odeyinka, M. Browne, C. Mckeown, and M. Yohanis, "An Analysis of the Drivers for Adopting Building Information Modelling," $J$. Inf. Technol. Constr., vol. 18, pp. 338-352, 2013.

[45] J. Boon, "Preparing for the BIM Revolution," in 13th Pacific Association of Quantity Surveyors Congress (PAQS 2009), 2009, pp. 33-40.

[46] P. Rajendran, T. Seow, and K. Goh, "Bulding Information Modeling (BIM) in design stage to assist in time, cost and quality in construction innovation," Int. J. Conceptions Manag. Soc. Sci., vol. 2, no. 3, pp. 52-55, 2014.

[47] J. Kim, "Use of BIM for Effective Visualization Teaching Approach in Construction Education," J. Prof. Issues Eng. Educ. Pract., vol. 138, no. 3, pp. 214-223, 2012.
[48] InfoComm International, "Building Information Modeling (BIM) Guide," 2011.

[49] R. M. Leicht and J. I. Messner, "Comparing Traditional Schematic Design Documentation To a Schematic Building Information Model," in Proceedings of CIB W78 24th International Conference on Information Technology in Construction, 1997, pp. 39-46.

[50] R. P. Kumanayake and R. M. P. S. Bandara, "Building Information Modelling (BIM); How It Improves Building Performance," in International Symposium on Ensuring National Security Through Reconciliation \& Sustainable Development, 2012, pp. 357-365.

[51] J. Boshoff, "Building Information Modelling (BIM)," Civil Engineering, no. March, p. 56, 2014.

[52] Z. Ma and Z. Liu, "BIM-based Intelligent Acquisition of Construction Information for Cost Estimation of Building Projects," Procedia Eng., vol. 85, pp. 358-367, 2014.

[53] P. Demian and D. Walters, "The advantages of information management through building information modelling," Constr. Manag. Econ., pp. 1-13, 2013.

[54] N. Alp and C. Manning, "Creating a Plan for Building Information Modeling," pp. 2732-2734, 2014.

[55] A. Gerrard, J. Zuo, G. Zillante, and M. Skitmore, "Building Information Modeling in the Australian Architecture Engineering and Construction Industry," in Handbook of Research on Building Information Modeling and Construction Informatics, J. Underwood and U. Isikdag, Eds. IGI Global, 2009, pp. 521-544.

[56] A. Sawhney and P. Singhal, "Drivers and Barriers to the Use of Building Information Modelling in India," Int. J. 3-D Inf. Model., vol. 2, no. 3, pp. 46-63, 2013.

[57] G. Aranda-mena, A. Chevez, J. Crawford, R. Wakefield, T. Froese, J. Frazer, S. Gard, and D. Nielsen, "Business Drivers for Building Information Modelling," 2008.

[58] V. Popov, V. Juocevicius, D. Migilinskas, L. Ustinovichius, and S. Mikalauskas, "The use of a virtual building design and construction model for developing an effective project concept in 5D environment," Autom. Constr., vol. 19, no. 3, pp. 357-367, May 2010.

[59] NBS, "NBS National BIM Report 2014," 2014.

[60] C. Mccartney, "Factors Effecting the Uptake of Building Information Modeling (BIM) in the Auckland Architecture , Engineering , \& Construction (AEC) Industry," 2010.

[61] D. A. Campbell, "Building Information Modeling: The Web3D Application for AEC," in Web3D 2007, 2007, pp. 173-177. 